\title{
Towards a Policy that Supports People-Centered Housing Recovery-Learning from Housing Reconstruction after the Hanshin-Awaji Earthquake in Kobe, Japan
}

\author{
Elizabeth Maly* and Yoshimitsu Shiozaki \\ Department of Engineering, Kobe University, Kobe 657-8501, Japan
}

\begin{abstract}
The goal of disaster recovery is for survivors to regain stability in their lives, livelihoods, and housing. A people-centered housing recovery requires that residents are empowered to make decisions about their housing reconstruction, and that policies create housing options that support the ability of all residents to reconstruct their homes and lives. The 1995 Hanshin-Awaji Earthquake caused the largest amount of damage in Japan since World War II, and the subsequent recovery is a starting point for understanding contemporary post-disaster housing reconstruction policies in Japan. Beyond an overview of housing reconstruction programs, we can understand the impact these policies had on Kobe residents' housing and community recovery. In many cases, housing policies implemented after the Kobe earthquake fragmented communities and caused further damage and disruption in the lives of the survivors. A single-track approach failed to support the entire population of the disaster-stricken area. In subsequent years, Japanese disaster reconstruction laws and policies have seen modifications and improvements. Some of these changes can be seen in cases of recovery after more recent disasters, notably after the 2004 Chuetsu Earthquake in Niigata Prefecture. In the context of these past examples, we can consider what is needed for a people-centered recovery in the Tohoku area after the 2011 Great East Japan Earthquake and Tsunami.
\end{abstract}

Keywords Hanshin-Awaji Earthquake, housing policy, housing reconstruction, Kobe, people-centered housing recovery

\section{Introduction}

This article considers the concept of people-centered housing recovery and how it can be applied in the Japanese postdisaster context. The housing recovery process after the 1995 Hanshin-Awaji Earthquake is reconsidered within the framework of people-centered housing recovery. Our assessment is based on key sources published in English that describe and explain the housing reconstruction process in Kobe and more recent changes in policies that affect housing recovery and

\footnotetext{
* Corresponding author. E-mail: lizmaly@gmail.com
}

reconstruction in Japan. After clarifying the main aspects of housing recovery in Kobe and key differences in later recovery processes, especially after the 2004 Chuetsu Earthquake in Niigata Prefecture, we offer some recommendations towards a more people-centered housing recovery after the 2011 Great East Japan Earthquake and Tsunami in Tohoku.

The following section introduces the term "peoplecentered housing recovery" in the context of related terms used in disaster recovery literature and posits key aspects of people-centered housing recovery in Japan. We then focus on two primary aspects of the basic housing recovery policy after the Hanshin-Awaji Earthquake: (1) the main single-track approach of the reconstruction process, in which the government built temporary housing and then permanent public rental housing; and (2) the lack of compensation or support for homeowners to rebuild their houses or privately owned rental structures. We then summarize subsequent changes in housing reconstruction policies and processes, especially after the 2004 Chuetsu Earthquake, considering how they became more people-centered, including policies for public housing construction, compensation for damaged private housing stock, consideration for keeping communities together, and flexibility in reconstruction options at the community and individual levels. After reflecting on the cases of housing recovery in Kobe and Niigata, we conclude with some thoughts about possible people-centered housing recovery in the Tohoku region.

\section{People-Centered Housing Recovery}

The term "people-centered" or the phrase "putting people at the center" has gained traction within the international post-disaster reconstruction community and has been defined as a basic and fundamental approach to disaster recovery. In a section titled "Achieving People-Centered, Integrated Reconstruction," the World Bank publication Safer Homes, Stronger Communities explains the fundamental importance of a people-centered aspect of disaster reconstruction: 
It can't be emphasized strongly enough that the affected population should be at the center of the reconstruction process and should have preferential right to make the decisions that will affect their lives... [the] government's first job after a disaster, with the help of humanitarian and development agencies, is to determine what the community is capable of doing. The government should then do the rest. (World Bank 2010, 7)

Recent publications from several other international development organizations dealing with disaster recovery work also include "the importance of a people-centered approach"i (UN-Habitat 2010) and the idea that "people must be at the center of human development" ii (UNDP 2011). After the 2004 Indian Ocean Tsunami, the Indonesian government adopted the principle of a people-centered recovery process (BAPPENAS 2005), which has also been endorsed by the Asian Coalition for Housing Rights and collaborators in Sri Lanka $^{\text {iii }}$ (ACHR 2005). In these examples, we can see that "people-centered" is usually used to refer to the process while "putting people at the center" of the reconstruction is equated with members of the affected population making the decisions that will shape the recovery.

\subsection{Housing Reconstruction Approaches}

The literature classifies international housing reconstruction projects into several main approaches based on who is controlling the rebuilding process, including both the funding and actual construction. The "owner-driven" approach to housing reconstruction is one that has been identified as a specific way of putting people in charge of their own recovery choices. Owner-Driven Housing Reconstruction Guidelines states, "whether we call them owner-driven, communitybased or assisted self-help projects there is evidences of growing interest in the use of participatory approaches for post-disaster recovery and reconstruction" (IFRC 2010, 5). International groups working in disaster reconstruction increasingly support and endorse the owner-driven approach. In a comparison of different housing provision approaches used in reconstruction in Gujarat, Barenstein defines the owner-driven approach as that which

\footnotetext{
enables communities to undertake building work themselves, with external, financial, material and technical assistance. Owner driven reconstruction does not necessarily imply that owners build the house on their own, but that, within given building codes, they retain full control over the housing reconstruction process. (Barenstein 2006, 2)
}

Although owner-driven housing recovery is one example of a people-centered process, it targets one group of residents only (home owners) while excluding others (renters, those without formal housing tenure). However, the idea behind the owner-driven approach is crucial for a people-centered housing recovery: residents retain control over the process of rebuilding their own houses.

While the term "owner-driven" usually describes a reconstruction process after disaster, when funding or materials are provided to residents who then build their own homes, after the earthquake in Kobe there were a number of cases where home owners also took the lead in reconstructing their own temporary housing without external support. The Japanese word jiriki literally means "self-power," and it is used to describe buildings that were constructed after the Kobe earthquake through the efforts of the residents themselves, especially self-built temporary housing. As is the case with owner-driven housing reconstruction in general, residents did not necessarily do the actual construction of this self-built housing in Kobe themselves.

\subsection{Participation}

There are several authors who use the term "people-centered housing reconstruction," notably Lyons, Shilderman, and Boano (2010) in Building Back Better: Delivering PeopleCentered Housing Reconstruction at Scale. The contribution of this publication is to "analyze the potential for large-scale reconstruction to be participatory and developmental for and of ordinary people - 'people centered reconstruction"' (Lyons, Shilderman, and Boano 2010, 2). As they claim that "donor-driven reconstruction is inappropriate, and ownerdriven reconstruction is too exclusive" (Lyons, Shilderman, and Boano 2010, 7), these authors emphasize the importance of shifting from supply-driven relief mode to a reconstruction mode that ought to be more support-driven and peoplecentered. The idea of people-centered housing recovery is closely connected with participation in the planning or design process, and the term is often used interchangeably with owner-driven and self-built.

\subsection{Putting People at the Center-Housing Policies that Support Life Recovery}

People-centered housing recovery can be understood as a concept that calls for residents to play a central role in making reconstruction decisions, and also supports owner-driven and/or self-built reconstruction. Yet beyond these important aspects, people-centered housing recovery can be considered to be a broader concept including policy, process, and housing design.

Along with the full participation of residents, peoplecentered reconstruction also needs official policies that are supportive of comprehensive solutions for all members of the community. Involving residents and even putting them in control of reconstruction decisions is not enough. Residents' opinions and housing needs must be addressed and supported by reconstruction policies and their implementation. A successful and people-centered recovery requires support from government, timely decisions and clear information, adequate and equitable funding, and policies that lead to a smooth housing recovery, with no gaps in beneficiaries and minimal delays.

To be accountable to residents' housing needs, housing reconstruction policies must support the life recovery of 
disaster survivors. This article considers how Japan's housing reconstruction policy could be more people-centered, and support the life recovery of disaster survivors through sufficiently addressing post-disaster housing needs. While people-centered housing recovery also has a relationship with more detailed aspects, such as citizen participation methods and specific urban planning issues such as land readjustment and redevelopment, the focus of this article is on the role of housing policies that support a people-centered recovery.

\subsection{People-Centered Housing Recovery Issues in Japanese Policy}

Japan is a developed country with extensive experience facing disasters and an established legal framework and government policy dealing with disaster prevention, response, and reconstruction. The housing reconstruction process in Japan is extremely standardized (from evacuation, temporary housing, to permanent housing) and organized by the government. The underlying principles of people-centered housing reconstruction apply directly in Japan at the levels of (1) overall policy that supports the residents and a housing recovery that supports their life recovery; (2) the involvement of community members and their opinions in the recovery process; and (3) support for the reconstruction of housing that matches the needs and desires of the residents for their living environment, which is closely connected to the existence of sufficient options so that residents have the ability to make choices for housing reconstruction that support their life recovery.

During the recovery after the 1995 Hanshin-Awaji Earthquake in Kobe, several issues crucial to a people-centered housing recovery stand out. (1) The needs of all disaster survivors should be equitably addressed regardless of age, gender, land or building tenure, family structure, and level of housing damage. (2) The housing recovery process should be as smooth as possible, with limited relocation and lifestyle disruptions. (3) Communities should be kept together if possible and their return to former neighborhoods should be supported (in accordance with hazard mitigation).

\section{Housing Damage after the Hanshin- Awaji Earthquake}

The magnitude 7.2 Hanshin-Awaji Earthquake on 17 January 1995 killed over 6400 people and destroyed over 240,000 houses. Much of the damage was concentrated in dense low-rise areas of Kobe City where older wooden houses were common. These wooden houses, many of them low-rent row houses, caught fire after the earthquake. Because earthquake debris blocked the narrow streets there was no way to get emergency vehicles into these areas, and with rare exception when neighbors were able to extinguish them quickly, these fires burned for days, completely destroying whole neighborhoods. Compared to Kobe City in general, the areas that burned were predominantly home to lower-income residents and accordingly high concentrations of cheap privately owned rental housing. Rent for old wooden housing is affordable because of the buildings' age, and once destroyed, it is extremely difficult to replace this affordable housing stock. Housing damage was therefore especially severe for the vulnerable (low-income) tenants in these areas.

\subsection{Temporary Housing}

At the peak, there were 220,000 displaced victims staying in 599 emergency shelters (Hirayama 2000). The government refused to distribute any cash assistance for rebuilding, instead relying on in-kind support in the form of temporary housing units based on the provisions of the Disaster Relief Act. Edgington argues this was clearly incompatible with the large-scale devastation and needs in post-earthquake Kobe (Edgington 2010, 58). Based on the Disaster Relief Act, temporary housing in Japan is limited to households unable to help themselves. People whose houses are completely destroyed by fire, collapse, flood, or are unable to find houses with their own funds qualify (Hirayama 2000).

Temporary housing was mainly a single story steel barracks type, with 2 rooms and up to $26 \mathrm{~m}^{2}$ floor area per unit. These were built quickly and uncomfortably hot in summer and cold in winter. With 149,000 units of housing damaged in the quake, the Japanese national government provided funding to the local government to build and manage 48,500 temporary housing units. The first 30,000 were completed by the end of March 1995; the rest were completed by August, seven months after the earthquake (Edgington 2010).

The main problems with temporary housing were inconvenient location on the outskirts of the city, low quality construction materials, cramped living spaces, lack of convenient medical and shopping facilities (Hirayama 2000), and lack of insulation and sound proofing. Temporary housing sites in Kobe lacked social facilities, green spaces, and many were built in isolated areas. The number of people living in temporary housing decreased gradually, although three years after the earthquake, there were still about 14,000 households living in temporary housing. As of April 1998, 45 percent of the temporary housing units were still occupied (Hirayama 2000).

\subsection{Location of Temporary Housing-Inconvenient for Daily Life}

To construct the large number of needed housing units, it was difficult to find available publicly-owned land, as required by law. Kobe City happened to own some open land that was planned for development, but it was in remote locations, which made it difficult for people living in temporary housing there to commute to work. Many people therefore chose to stay in emergency evacuation centers or parks (instead of moving into temporary housing) up to a year after the earthquake, until they were forced to move out (Edgington 2010). 


\subsection{Gaps between Those Who Wanted, Needed, and Entered Temporary Housing}

Although the policy created by Hyogo Prefecture did not apply any strict criteria for entering temporary housing, not everyone who wanted or needed temporary housing received it, due to construction delays, lack of supply, and beneficiary gaps that were created in the selection process. Hirayama (2000) explains that in order to qualify for temporary housing, it was important that applicants were staying in an evacuation shelter at that time; when the evacuation shelters closed, the construction of temporary housing also stopped. In addition, many victims gave up on receiving temporary housing because of the long construction times. Therefore, fewer people actually moved into temporary housing than had hoped to. People who did not enter temporary housing, and had to find alternative housing even temporarily, in some cases became left out of further public programs. One reason for this is that people who were living elsewhere did not have access to all of the reconstruction information that was distributed mainly to residents of government supplied temporary housing. Although neighborhood and community groups made efforts to circulate newsletters to former residents, many people who moved away from their former neighborhoods did not receive this information, and it was not always easy for them to stay informed and know the most current information regarding opportunities that would have been available to them during the later reconstruction process, such as compensation for land or eligibility for public housing.

\subsection{Temporary Housing Units Assigned by Prioritized Lottery-Randomized Entry}

Temporary housing units were allocated through a lottery system, which gave priority to the elderly, disabled people, or other vulnerable groups. While the idea to provide additional support to vulnerable members of the community is admirable, it does not consider the entire community, excludes many from needed support, and does not take into account the effect of grouping vulnerable populations together in temporary housing. When the impact on overall community networks is considered holistically, the randomized selection of temporary housing residents led to communities being fragmented and displaced from their former neighborhoods, and also to high concentrations of elderly people in temporary housing. Being displaced from where they had lived their whole lives and not knowing any of their neighbors was especially hard for elderly residents, who made up 30 percent of temporary housing residents, although they made up only 14 percent of the city's overall population in 1995 (Edgington 2010). "Solitary death," where elderly residents passed away without anyone noticing, became a recurring issue in both temporary and later in public housing and meant that many elderly people were living without any social connections. The temporary housing program led to the creation of a group with a serious need for support-overwhelmingly lowincome and elderly individuals (Hirayama 2000). In December 1995, 47 percent of households in temporary housing had elderly members, in February/March 1996, 42 percent of households in temporary housing had elderly members (Hirayama 2000). Only 40 percent of temporary housing residents were employed, and 34 percent lived on a retirement pension. About 29 percent of people living in temporary housing earned less than 1 million yen per year (approximately USD 10,000 in 1995/1996) and 70 percent earned less than three million yen (Hirayama 2000).

\section{The Single-Track Approach: From Temporary Housing to Public Housing}

After the Hanshin-Awaji Earthquake, the main governmental support for housing recovery in Kobe took the form of material compensation in a one-size-fits-all solution: temporary housing construction, followed by "disaster recovery public housing" construction. Koshiyama (2011) outlines the general argument for this solution, which is that it supports the lowest income segments of the population, although it can also be criticized as an inflexible single-track approach. One main problem with this single-track approach was that it ignored and provided no support for homeowners or landlords who wanted to rebuild their houses, apartments, or shops, focusing instead on one single way to provide housing for only the most desperate segment of the population, while leaving everyone else to fend for themselves. In addition, the single-track approach was inflexible because if residents deviated from it during an earlier phase (emergency shelter, or later temporary housing) they were unable to regain access to the support in the later phase (temporary housing or public housing). People who chose to stay near their place of employment, children's school, or their own business instead of entering temporary housing could not receive any housing support. If the temporary housing within the single-track did not match the residents' housing needs, there were no other options besides relying on their own means. Along with these problems intrinsic to an inflexible single-track approach, there were a number of specific problems with temporary housing as it was provided in Kobe. These include the livability of the units themselves, inconvenient and distant locations, and the entry process with lotteries as well as long waiting times, which repeatedly scattered former communities during multiple phases of the process. While not all of the temporary housing was in locations far from original residential areas, it was the norm. Small business owners faced an additional hardship, as moving away from their former neighborhoods to disaster temporary housing made it almost impossible to rebuild their stores and companies.

Although not as well known, there were many examples of residents who rather than following the government-supported single-track approach, constructed their own self-built temporary housing or business. This does not mean necessarily 
that they did the construction themselves, but rather they paid for, and provided these structures for themselves. There was no support from the government for these efforts. Compared to temporary housing provided by the government, self-built housing allowed residents to stay close to their former neighborhoods; self-built reconstruction was often the best option for rebuilding stores or businesses, as it allowed business owners to restart their operations in their former customers' neighborhoods. The single-track approach in Kobe of temporary housing followed by the provision of disaster recovery public housing, recreated many of the same challenges for residents twice-remote locations, randomized entry by lottery (fragmenting communities), and long waits. Since the single-track approach included both of these stages that could be very disruptive to the lives of the residents, self-built housing had the advantage of providing continuity for the dweller, not requiring multiple moves, and preventing dislocation from their original neighborhood. For those who used the self-built structures for companies or stores, it allowed them to resume business more quickly, which has an obvious positive effect on livelihood recovery. In addition, the cost of temporary housing, paid by the national government, is for a disposable structure- only used for 2-5 years. In contrast, self-built housing allows the value invested in the house to be accrued, and not discarded. Yet there was no provision for government to support this kind of housing reconstruction after the Kobe earthquake or other more recent disasters.

\section{Permanent Housing Reconstruction in Kobe-Government-Driven}

The government's permanent housing recovery policy for the victims of the Hanshin-Awaji Earthquake was to provide disaster recovery public housing. Similar to the temporary housing phase where there was one single type of support available, although there were some alternative types of recovery housing (co-operative housing, elderly support housing, and so on) disaster recovery public housing was the only choice available for most disaster victims. As opposed to the owner-driven approach introduced in section 2, official housing reconstruction in Kobe was completely governmentdriven, with beneficiary residents having very little choice or control over their housing options. Similar to temporary housing, most public housing was also located far from residents' former neighborhoods, and made it difficult for them to recover their daily life. Relying exclusively on public housing, the housing recovery process included almost no support for homeowners or landlords to rebuild homes or rental properties.

\subsection{Permanent Disaster Recovery Public Housing}

The basic plan for permanent housing recovery was the Kobe City Emergency Three Year Plan for Housing Reconstruction, which was made public in July 1995 (Hirayama 2000). It called for 72,000 units of housing to be started between 19951997; 10,000 units (14 percent) were planned as public housing for low-income people; and 30,500 units (42 percent) were planned as publicly subsidized housing, including semipublic housing, replacement (mainly low-income) housing related to redevelopment, and subsidized moderate-income private rental housing (Hirayama 2000). A year later, in July 1996, the Kobe Housing Restoration Plan was released. Based on the serious situation of temporary housing and the needs of the poor and elderly, the number of public housing units was increased from 10,000 to 16,000 . This increase was to be achieved by leasing private rental housing as well as the construction of new housing. The overall number of housing units in the plan remained 72,000 (Hirayama 2000). In total, there were 24,512 new public housing units constructed in Kobe (Olshansky et al. 2005), and whereas this is a significant number overall, the public housing provided in areas that had sustained the most damage did not come close to replacing the loss of 30,642 units of affordable low-rise wooden housing in Kobe. For example, in Nagata Ward, which had lost 11,711 houses, there were only 3171 units of public housing provided (Olshansky et al. 2005).

Additional subsidies from the central government were introduced to reduce public housing rent. An amendment to the Public Housing Act of 1996 created an income-sensitive rent system. Rent was based on income, location, and size of the unit. The additional state subsidy was to continue for five years after moving in (Hirayama 2000) and was subsequently extended several times. Although income restrictions for public housing were loosened, 30 percent of units were reserved for elderly, disabled, and single-parent families as priority housing. The process for entering disaster recovery public housing gave a priority to temporary housing residents. In July 1996, 60 percent of new public housing units were set aside for temporary housing residents; if an applicant was not selected by lottery for the 60 percent reserved for temporary housing residents, he or she could try again for the remaining 40 percent of the spaces available for general victims. In April 1998 , the number of public housing units reserved for temporary housing residents was increased to 80 percent (Hirayama 2000). The demand for public housing far outstripped the supply. By May 1998 there were 123,740 applications received for the 26,559 units (Olshansky et al. 2005).

Murosaki (2007) identifies three problems with the provision of public housing: it was limited to elderly and low-income groups; construction took a long time; and distant locations meant that many victims left the earthquakestricken area. As was the case with temporary housing, the process for entering permanent disaster recovery public rental housing caused disruption in the lives and communities of disaster survivors. Once again, the single-track approach meant that although there were problems with the process of entering and/or living in disaster recovery public housing, there were few other support mechanisms in place to help low-income residents rebuild their homes besides relying on disaster recovery public housing. 


\subsection{Public Housing within Japan's Two-Tiered System}

As Hirayama (2000) explains, Japanese housing policy is a two-tiered system. Policies supporting home ownership, including low-interest loans, are directed at people who are expected to purchase or rent their home as a market commodity. Public housing is built and owned by the government, and rented to low-income households, and beneficiaries are limited. Policies for housing recovery are based on this same framework, and although the scale of housing destruction led to the mass construction of temporary housing and then permanent public housing, inverting the usual ratio of welfare and self-help housing, the two-tiered system itself remained constant (Hirayama 2000).

Hirayama (2000) explains how the two-tiered system divided earthquake victims socio-spatially and ignored the diverse situations of the victims:

In reality, the victims have diverse needs in regard to public resources: victims in need of effective support, households in need of complementary support and those with the ability to help themselves. However, if the principle of self-help is applied, most of the earthquake-hit people are forced to reconstruct their houses through their own efforts and welfare housing supply necessarily becomes residual. (Hirayama 2000, 120)

Actually, those in the self-help group under the two-tiered system also may need public support for reconstruction, but are excluded, as there was no provision for support outside the welfare housing track of the two-tiered system. At the same time, those receiving support in the form of public housing may become segregated, leading to stigmatization.

\subsection{Minimal Support for Private Reconstruction}

This rigid two-tiered system leads to a housing recovery that is not people-centered in two connected ways. First, it creates huge gaps in beneficiaries - an entire sector of the population who cannot receive support for what they want to do, which is to rebuild or repair their formerly owned houses. Secondly, through this exclusion, the policy actively denies residents the option to make their own housing choices. With no support for reconstruction of private homes, people without their own sources of financial means were faced with public housing as their only option. Not only were they not able to choose their own housing situation, but by excluding the option of reconstruction, residents' control over their own living environment was drastically reduced. Private housing provides more flexibility for designs that match the residents' needs, while with few exceptions, Japanese public housing units are uniform and not adaptable, and in high-rise buildings. In addition to homeowners, shop owners and landlords (including those of private affordable rental housing) had no access to support, which in turn left their former tenants with few options, as even the subsidized rents were too expensive for the target group.
After the Kobe Housing Restoration Plan of July 1996, the City of Kobe launched various programs to encourage house rebuilding in the urban area: temporary rent subsidies for those who moved into private rental housing, loans for the elderly for reconstruction of their houses holding a mortgage on real estate, aid for projects in which two or more victims construct housing collectively on a site obtained by combining small lots, and aid for projects in which narrow streets are made wider. However, these programs had limited coverage and were difficult to carry out, especially those that required agreement among multiple landowners, such as joint and cooperative housing.

Disaster survivors wanted to return, but it was very difficult to find or rebuild replacement housing in their former neighborhoods. Two reasons for this were that most people in Kobe did not have any insurance money, and there were no loan agencies they could borrow from, at least initially. There were some low-interest loans available from the Housing Loan Corporation, Hyogo Prefecture, and the City of Kobe created a low-interest housing loan program from the Hanshin Earthquake Recovery Fund, which made loans to homeowners and condominium owners with no other funding for repairs (Edgington 2010). However, elderly residents did not have enough credit to access these programs. Double loans (taking out another loan for rebuilding in addition to an original loan) was another hardship faced by local residents. Working-age people were forced to take out extra loans for rebuilding their homes. Younger people and/or landowners were often able to rebuild in a year or two (Edgington 2010). Older people, those who owned land but did not have other resources, or those who had been living in private rental housing had no other choice but to rely on public housing assistance (Edgington 2010).

\subsection{Reconstruction of Private Affordable Rental Housing}

After the earthquake, rental housing was in short supply, as many units of affordable, privately owned rental housing had been destroyed by the fires. While public housing was meant to replace low-rent private rental housing, it failed to do so (Hirayama 2000). Low-rent private rental housing was in urban areas, with many choices for residents and no criteria for income or identification. Public housing is difficult to construct in large numbers in urban areas, requires income and identification qualification, and has long and complicated move-in processes. Hirayama (2000) identified these as crucial issues for low-income renters, which means that many former residents of low-rent private apartments that were destroyed would not have been eligible for formal rental contracts due to a number of factors such as insufficient income, lack of established registration or guarantor. If only the number of units is considered, rental housing lost due to the earthquake was replaced by new constructions. However, this is not the case when affordability is considered. Although categorized "affordable," these new, often mass-produced, 
studio or prefabricated units require security deposits and higher rents compared to older private rental housing. These new units are therefore out of reach of the low-income residents who relied on private rental housing pre-quake. This kind of very cheap housing is impossible to replace, since the property owners rarely have the means or the motivation to rebuild it, as the rent they could collect is much lower than the construction cost they would have to pay.

\section{Changes in Housing Reconstruction Policy since the Hanshin-Awaji Earthquake}

Faced with the urgent need to provide temporary and then permanent housing in large numbers after the HanshinAwaji Earthquake, the government's large-scale plans (mass temporary housing sites followed by high-rise public housing, both located far from former neighborhoods and the city center) did not carefully consider the detailed impact on the daily lives of the affected residents at the community level. Temporary housing and public housing recovery policies also created displacement from which many severely stricken communities could not recovery.

The single-track approach left many people with no support, and public housing, which was the main focus of permanent housing reconstruction, also created difficulties for residents. The strict limitation on spending public funds to compensate private homeowners had a detrimental effect on residents' abilities to rebuild. From the example of Kobe, the detrimental effect of mass relocation and scattering of communities was understood, as well as support needed in addition to the construction of physical housing alone.

In the years since the reconstruction in Kobe, some reconstruction policies have been modified, and have provided broader and more comprehensive support for survivors of later disasters, notably the 2004 Chuetsu Earthquake in Niigata Prefecture. Restrictions on providing compensation for private homeowners have been eased and disaster recovery public housing has been built at a smaller scale that is more community-friendly. The benefit of keeping communities together through the entire resettlement process, and the special needs of elderly evacuees and others is much better understood, and these issues are increasingly considered along with the physical reconstruction. Reconstruction programs have moved away from the single-track approach used in Kobe, although some groups are still left out of the reconstruction assistance programs.

Since the context of each disaster is unique, there are undoubtedly aspects of the reconstruction process in Niigata Prefecture beyond policy that have influenced recovery. However, post-disaster recovery processes that occurred after disasters in later years following Kobe's reconstruction, especially in Chuetsu, clearly show the impact of housing reconstruction policy changes. Key aspects of these modifications and their implementation can been seen in the programs for temporary housing and permanent housing reconstruction, especially compensation for homeowners.

\section{1 Temporary Housing after the Chuetsu Earthquake}

Nine and a half year after the earthquake in Kobe, the magnitude 6.8 Chuetsu Earthquake struck a rural mountainous area of Niigata Prefecture on 23 October 2004. Compared to Kobe, there were fewer casualties-39 people lost their lives. The scale of housing damage was severe, with over 100,000 people evacuated from their homes during the peak time of the first few days. This number steadily decreased, to 80,000 after one week, and 6500 after a month (Iuchi 2010b). In the following temporary housing phase, there were 3460 temporary housing units constructed. At the peak time in March 2005, there were 9649 people in 2935 households living in temporary housing (Iuchi 2010a).

Iuchi explains how governments in the region looked to the example of what had happened to communities in Kobe and tried to avoid repeating "bitter lessons learned from the 1995 Hanshin-Awaji Earthquake, in which shelters provided at isolated sites disrupted community ties and intensified mental isolation and depression of the victims" (Iuchi 2010a, 71). Local government made every effort to support a recovery process that kept communities together and minimized displacement, and were "particularly careful about restoring the social fabric of affected communities throughout the entire process of resettlement" (Iuchi 2010a, 9). This was supported in many ways, including the design and layout of temporary housing and the creation of welfare support facilities on site.

\subsection{Permanent Housing Reconstruction}

As had been the case in Kobe, disaster survivors after the Chuetsu Earthquake had two options for permanent housing: rebuilding on their own or moving into public housing built by the government. However, compared to the experience of Kobe, both of these options were supported in ways to lessen the negative impact on residents and communities. Public housing was constructed at a smaller scale than the high rises in Kobe, and residents were more likely to know their neighbors, as communities had been kept together throughout the resettlement process. In the case of Yamakoshi Village, public housing was even constructed within the former community, to preserve the community ties (Iuchi 2010a, 87). After the Chuetsu Earthquake, 336 units of affordable public rental housing were constructed, and another 121 units were provided for disaster-affected households using regular affordable housing programs (Iuchi 2010a, 79). All disaster survivors had moved out of temporary housing after three years, and relatively few public housing units were built compared to the number of households in temporary housing. Public housing was necessary to support the elderly population who was unable to rebuild on their own. However, the financial support that was made available to homeowners in Chuetsu made it much easier for them to rebuild than it had 
been for the Hanshin-Awaji Earthquake survivors. In addition to direct compensation, there were several programs that targeted communities to promote livelihood recovery after the Chuetsu Earthquake. These included a collective relocation program for disaster prevention, a similar program for residential relocation from cliff areas that does not require collective relocation, and a residential area improvement program that is not usually used after disasters (Iuchi 2010a). Although these programs represented more variety and different recovery options for communities in the disaster area, their benefit to individual households was strictly limited to those families that were following the same recovery approach selected by the community. In communities that selected group relocation, there was no support for residents who chose to rebuild on site. Conversely, in communities that selected rebuilding, there was no support for residents who relocated.

\subsection{Compensation for Homeowners}

For disasters in Japan before the 1995 Hanshin-Awaji Earthquake, private donations were the main source of money for rebuilding. After the 1991 Unzen volcano eruption and the 1993 Okushiri earthquake and tsunami, victims received more than USD 85,000 (10 million yen), which they could use to offset the cost of rebuilding their houses (Maki 2007). After the Hanshin-Awaji Earthquake, donations received constituted a huge sum, but the number of victims was also immense, so the amount that was distributed to each victim family was only USD 3300 (400,000 yen) (Maki 2007).

As Iuchi explains, "national laws supporting affected individuals do not exist," since traditionally governments in Japan do not provide financial support directly to individual households as compensation for destroyed private property (Iuchi 2010a, 77). However, since the Hanshin-Awaji Earthquake there have been some changes in laws dealing with recovery. In April 1996, the Act on Support for Reconstructing Livelihoods of Disaster Victims was approved and a new Victims Life Recovery Support Act was put in place in 1999. This law supplied up to USD 8000 ( 1 million yen) per household in a grant for life recovery (Maki 2007).

After the Chuetsu Earthquake in 2004, the amount specified in the law was increased to USD 25,000 (3 million yen) through the addition of the Housing Related Support Grant in an amount up to USD 17,000 ( 2 million yen); however, this money still could not be used for housing construction or repair - it could be used only to dismantle housing, pay loan costs, or rent (Maki 2007). Subsequently expanded to allow support for housing demolition and removal, each household could receive up to 3 million yen, according to housing damage, income, and age of the household head, and $2 / 3$ of this amount could be used for housing demolition and removal. In addition to this fund from the national government, Niigata Prefecture provided a similar program that was less restricted by age or income, and financial support from the local government was allowed to be used for home rebuilding and rent (Iuchi 2010a). Iuchi (2010a) explains the Urgent Rehabilitation of Affected Houses program, intended to support residents to repair their existing disaster-damaged homes. In addition to the households who could qualify under the restrictions of the national program (based on income, housing damage level, not living in temporary housing), the program administered by Niigata Prefecture did away with the income qualification and restriction on living in temporary housing, and covered residents with totally collapsed houses. At maximum, households with severely damaged houses could receive up to 1 million yen, and 0.5 million yen for largely damaged houses (Iuchi 2010a).

Similarly, after the 2007 Noto Peninsula earthquake, also in Niigata Prefecture, homeowners were largely able to rebuild their houses, relying on a combination of financial support payments from the government, supplemented by loans, personal savings, or financial support from family members. Another example of similar support had been provided to residents after a 2000 earthquake in a rural area of Tottori Prefecture. Maki (2007) explains this case in which people who reconstructed their houses received a grant of USD 25,000 ( 3 million yen); and those who stayed in their original town received USD 12,500 to repair their houses. Part of the reason behind this program, which caused a governmental budget failure, was to try to keep people in a rural area already facing depopulation. These examples show in the years since the recovery after the Hanshin-Awaji Earthquake, the government changed policies and that there are some different possibilities for various support for homeowners.

\section{Housing Situation in Tohoku after the 11 March 2011 Earthquake and Tsunami}

The magnitude 9.0 earthquake that struck off the coast of northeast Japan on 11 March 2011 and the resulting tsunami caused damage of a severity and a complexity never seen before in modern Japan. Although Japan has some of the best disaster prevention systems and policies in the world and this region regularly experiences tsunamis every $30-40$ years, this tsunami of a scale that is repeated only every 1000 years exceeded all expectations and completely overwhelmed the disaster prevention measures in place. Close to 20,000 people lost their lives, including casualties and those who are designated as missing. The scale and complexity of the damage also makes the issues of recovery extremely complicated, and housing recovery is inextricably linked to other issues in the disaster stricken area, such as questions of relocation, land subsidence, lack of buildable land, and economic recovery in the context of an area that was already suffering from rural depopulation and a growing number of elderly residents. In addition, the nuclear accident at the Fukushima Daiichi reactor has added another layer of difficulty to the already complex challenges of reconstruction. In terms of the impact on housing recovery issues, evacuees fleeing nuclear radiation face extended or permanent displacement and their housing 
recovery is still uncertain. The scale of the current displacement - over 340,000 people remain displaced more than one year later-and the complicated nature of a vast disaster area that spans multiple prefectures and many municipalities makes reconstruction more difficult to implement. Within the disaster region there are huge differences between areas with respect to damage, geography, culture, and housing needs.

From the housing recovery processes after the earthquakes in Kobe and Niigata, there are both examples of what to replicate and to avoid, towards a goal of people-centered housing recovery. Although the negative impact of scattering residents randomly into temporary housing is known from the Kobe experience, this pattern has been repeated in many areas of Tohoku, as the scarcity of land and limitations of where temporary housing can be built makes it impossible to keep many former communities together. Similarly, although the impact of randomized lottery selection contributed to the dispersal of Kobe pre-earthquake communities, this system was also used in many Tohoku municipalities. There are, however, examples of communities that were collectively relocated into temporary housing, or moved into temporary housing near their former neighborhoods.

In the temporary housing units there are vast differences in quality of the buildings themselves as well as the surrounding living environment. Many of the same problems that plagued temporary housing in Kobe are being repeated in Tohokusuch as low-quality and uncomfortable housing, distant relocation, fragmentation of communities, and inconvenient locations lacking transportation. However there are also examples of innovative design and construction - areas where local materials/traditional carpentry were used, and examples of wood construction that creates a more pleasant living space. There are also rare examples of temporary housing areas that were designed to create a more community-friendly space, and there are many non-profit, volunteer, or official initiatives to create spaces and events for communitybuilding and psychological support in temporary housing areas.

In addition to the innovation in the form and quality represented by wooden temporary housing, another option used for the temporary housing phase represents a move toward people-centered housing: "designated temporary housing." In this system that was introduced but not widely used after the Kobe earthquake, local governments can rent existing privately owned housing units and provide them to disaster survivors, rather than constructing new temporary housing units. In December 2011, there were over 66,000 of these designated temporary housing units in use, compared to 52,000 conventional temporary housing units that were built after the disaster (Mainichi Daily News 2012). While there is the danger that people living in this housing type will be isolated from their former community or may lose access to recovery information, if these issues are resolved this system provides an important option for higher-quality housing at a lower cost to the government, and fewer delays in resettlement. Using multiple methods of housing also creates more flexibility in the rehousing process, which signifies a potential to respond to residents' varied housing needs, as well as more options for residents' choice in the housing process.

It remains to be seen to what degree the future permanent housing reconstruction in Tohoku will be people-centered. One year after the disaster, there are too many unresolved questions about housing relocation, compensation for housing damage, and construction of public housing, to know what shape reconstruction will take.

\section{Conclusions-Towards a People- Centered Housing Recovery}

People-centered housing recovery includes policy, process, and housing form and choices that support disaster survivors in their life recovery. Since the 1995 Hanshin-Awaji Earthquake in Kobe, housing reconstruction policy in Japan has improved in some ways to become more responsive to residents' needs. Looking ahead to consider housing recovery in the Tohoku region of Japan after the Great East Japan Earthquake and Tsunami, it is imperative that we learn from and improve on past examples, especially those of Kobe and Chuetsu.

The single-track approach in Kobe, wherein government supported only in-kind temporary housing, followed by disaster recovery public housing, did not provide compensation for owners of damaged homes. One of the most significant housing reconstruction policy changes since then is the current policy that provides financial support to homeowners. While this is clearly crucial support for a large number of disaster survivors, there are still restrictions based on the amount of damage sustained, which can leave residents with a partly damaged house that does not qualify for compensation unsupported.

The single-track approach to housing reconstruction in Kobe caused additional damage in the lives of disaster survivors. Specifically, the relocation, dispersal, and delays involved with living in typical temporary housing and disaster recovery public housing made it difficult for people to be able to rebuild their lives. The system that was implemented after the Chuetsu Earthquake was more successful in keeping communities together throughout the rehousing process, and in some cases keeping people close to former villages. Using various programs for relocation or resettlement, communities could chose different options for their recovery, although if individual residents made reconstruction choices that were different from the community as a whole, they were not supported. In terms of housing reconstruction, one of the key aspects of recovery in Chuetsu is the larger amount of financial support that was provided to homeowners, which had a significant impact in making it possible for them to rebuild their own homes.

Kobe's reconstruction was the first time in recent years that the Japanese government faced recovery after a large-scale urban disaster. Clearly vast improvements were 
implemented in housing recovery after the Chuetsu Earthquake, although the damage was of a much smaller and manageable scale, compared to Kobe's earthquake and the current situation in Tohoku. While the overall scale of the earthquake damaged area is much smaller, the scattered rural mountain communities that suffered disaster in Chuetsu may offer an important example for Tohoku, where there are also many smaller towns facing recovery. Providing an appropriate menu of options for these coastal communities and their residents will be an important part of reconstruction policy. The different communities in Chuetsu followed different process for reconstruction, including relocation and resettlement. Having options and incorporating flexibility in resettlement is a good start, and the options for individual residents must also be considered carefully.

Housing recovery in Tohoku will take many years, and the outcome is unknown. People-centered housing reconstruction in Tohoku will require resident participation and sufficient housing options (both public and private) that support people in rebuilding their lives, communities, and livelihoods. For a people-centered housing recovery in Japan, the two predictable options - support for private housing reconstruction and provision of public housing for disaster victims - need to be reconsidered to address the broader needs of all residents. Hopefully this will be the case in Tohoku, and housing construction options will be made available in a way that is responsive to the needs of all residents for their life recovery.

\section{Notes}

i UN-HABITAT underlines the importance of a people-centered approach, which instead of creating "passive victims," emphasizes "building on people's capacity, giving access to resources and responsibility for decision making" (UN-Habitat 2010, 2).

ii UNDP emphasizes that, "people must be at the center of human development, both as beneficiaries and drivers, as individuals and in groups. People must be empowered with the tools and knowledge to build their own communities, states, and nations" (UNDP 2011, 2).

iii BAPPENAS explains that after the 2004 tsunami in Banda Aceh, one of the principles adopted by the National Recovery and Reconstruction Strategy was: "A People-centered and participative process, where the administration listens to and understands the feelings and aspirations of the people" (BAPPENAS 2005, 2). In a Regional Meeting on the Post Tsunami People Centered Recovery Process in March 2005, organized in Sri Lanka by the Asian Coalition for Housing Rights (ACHR), in collaboration with Women Bank and Women Development networks and Sevanatha Urban Resource Center Slum Dwellers International (SDI) and the Center on Housing Rights and Evictions (COHRE), ACHR defined a "People Centered Recovery Process" as one in which victims are consulted on what they want and given as much self-determination as possible on how that is to be achieved (ACHR 2005).

\section{References}

ACHR (Asian Coalition for Housing Rights). 2005. Regional Meeting on Post Tsunami People Centered Recovery Process. http://www. achr.net/000ACHRTsunami/Tsunami/Tsuami\%20Extras/Sri\%20 Lanka\%20Meet.htm.

BAPPENAS (Badan Perencanaan dan Pembangunan Nasional, or National Development Planning Agency of Indonesia). 2005. Indonesia: Notes on Reconstruction, the December 26, 2004 Natural Disaster. http://siteresources.worldbank.org/INTINDONESIA/Resources/ Publication/280016-1106130305439/reconstruction_notes.pdf.

Barenstein, J. D. 2006. Housing Reconstruction in Post-Earthquake Gujarat. Humanitarian Practice Network Paper no. 54, March 2006.

Edgington, D. W. 2010. Reconstructing Kobe: The Geography of Crisis and Opportunity. Vancouver: University of British Columbia Press.

Hirayama, Y. 2000. Collapse and Reconstruction: Housing Recovery Policy in Kobe after the Hanshin Great Earthquake. Housing Studies 15 (1): 111-28.

IFRC (International Federation of Red Cross and Red Crescent Societies). 2010. Owner-Driven Housing Reconstruction Guidelines. Geneva: IFRC.

Iuchi, K. 2010a. Redefining a Place to Live: Decisions, Planning Processes, and Outcomes of Resettlement after Disasters. Urbana, IL: University of Illinois at Urbana-Champaign.

- 2010b. Reducing Vulnerabilities through Resettlement Planning in Disaster-Affected Communities: Relocation or Repopulation? In Tipping Points in Humanitarian Crisis: From Hot Spots to Hot Systems, edited by X. M. Shen, T. E. Downing, and M. Hamza, 81-89. United Nations University, Institute for Environment and Human Security.

Koshiyama, K. 2011. Comparison of International and Domestic Methods of Providing Housing after Disasters. Journal of Disaster Research 6 (2): 230-35.

Lyons, M., T. Shilderman, and C. Boano. 2010. Building Back Better: Delivering People-Centered Housing Reconstruction at Scale. London: Practical Action Publishing.

Mainichi Daily News. 2012. Problems Emerge after Local Governments Secure "Deemed" Temporary Homes for Disaster Victims. 17 January 2012.

Maki, N. 2007. How Can Public Sector Support Recovery of Privately Owned Individual Housing after Natural Disaster? Possibility of Setting Housing Recovery Grant in Japan. 2nd International Conference on Urban Disaster Reduction, 27-29 November 2007.

Murosaki, Y. 2007. Lessons on Reconstruction Strategies from the Great Hanshin-Awaji Earthquake. Journal of Disaster Research 2 (5): $330-34$.

Olshansky, R. B., L. A. Johnson, and K. Topping (with Y. Murosaki, K. Ohnishi, H. Koura, and I. Kobayashi). 2005. Opportunity in Chaos: Rebuilding After the 1994 Northridge and 1995 Kobe Earthquakes. University of Illinois, Department of Urban and Regional Planning. http://www.urban.illinois.edu/faculty/olshansky/chaos/chaos.html.

UNDP (United Nations Development Program). 2011. Annual Report from 2010/2011, People-Centered Development: Empowered Lives. Resilient Nations. New York: UNDP.

UN-Habitat. 2010. Shelter and Housing: UN-HABITAT in Disaster and Conflict Contexts. Geneva: UN-Habitat.

World Bank. 2010. Safer Homes, Stronger Communities: A Handbook for Reconstructing after Natural Disasters. Washington, DC: World Bank.

Open Access This article is distributed under the terms of the Creative Commons Attribution License which permits any use, distribution, and reproduction in any medium, provided the original author(s) and source are credited. 